\title{
The Progressive Training Mode of Computer Hardware Talents
}

\section{SHEN Shu ${ }^{1,2, a}$, SHAN Yue ${ }^{1, b}$, WEI Zhaoqing ${ }^{1, c}$ and JIANG Weile ${ }^{3, *}$}

${ }^{1}$ School of Computer Science, Nanjing University of Posts and Telecommunications, Nanjing, China

${ }^{2}$ Tongda Collage, Nanjing University of Posts and Telecommunications, Yangzhou, China

${ }^{3}$ College of Humanities, Xi'an Jiangtong University, Xi'an, China

ashens@njupt.edu.cn, bsy29930@sina.com, '18351927577@163.com

*Correspondence: jiangwl@xjtu.edu.cn

Keywords: hardware talents; theoretical courses; research projects; subject competition;

\begin{abstract}
The discipline of computer hardware is an important part of the computer professional training system. With the rising social requirements of computer hardware talents and the occurrence of some general problems in the process of computer hardware talents training, the quality of hardware talents training is declining in major China's universities. Therefore, there should be a transformation from the traditional separated, theoretical mode to the progressive mode, which is combined with theory and practice. This paper focuses on improving the scheme for the cultivation of hardware talents including three progressive levels, which are scientific research project, theoretical course study, competition guidance. Taking Nanjing University of Posts and Telecommunications as an example, this paper describes how to explore and innovate the teaching mode for hardware talents according to the direction of computer hardware development and the requirement of personnel training.
\end{abstract}

\section{Introduction}

Computer hardware talents is one type of professionals required in the computer field, and have the independent commitment to the design and application of computer hardware professionals. In current China's colleges and universities, the training goals of the computer hardware talents are not clear, as well as the ambiguous academic characteristics. As a result, it is "wide and not fine" in the actual training process and the students have insufficient expertise in hardware. Especially in hands-on practice, students cannot be well qualified for computer hardware professional work. There arise a lot of problems such as lack of experimental equipments, inharmonious of theoretical study and practice as a result of most colleges and universities ignoring the training of hardware-based hands-on ability, which severely limits the improvement of hardware hands-on ability.

For a long time, due to the professional development of computer hardware behind the software profession and some problems existing in the training objectives, courses, teaching and other aspects, it is necessary to improve the way of training the existing computer hardware students. Scholars have done some research in improving the practical ability of college students. Based on the present situation of the current undergraduate tutor system, the authors of [1] elaborated the role and guidance form of the tutor system in undergraduate education, and proposed the implementation strategy of the tutor system. [2] introduced a practical teaching system which combined knowledge with skills for computer science students. Reference [3] used Harvests of the application of task-driven method which was based on the theory of constructivism in order to cultivate students' abilities in terms of studying by themselves, analyzing and solving problems. [4] described student competitions providing an unparalleled source of motivation for students to solve real world problems. Blended Learning for hardware course education was adopted in [5], which combined virtual lab with actual lab to achieve better effect in practice. In order to awake students' curiosity in teaching hardware based courses, [6] described a new systematic approach which revolves around three steps. 
In this paper, based on some current work of undergraduate's tutor, course teacher, class sponsor, the authors try to explore a training shceme in order to improve the students' practical ability in hardware-based course and project, which includs the project, couse study, and disciplines competition three progressive links.

\section{General framework}

The progressive cultivation methods are designed to reflect computational thinking in the training process. The ultimate goal is to cultivate a certain degree of thinking ability of the hardware professionals. Fig. 1 is the overall program of the hardware-based progressive model. The first part is "scientific research project guidance". Through a project-driven way, students can understand the theory of thinking in practice under the guidance of teachers. The second part is "theoretical course learning”. Teachers need to strengthen the links between disciplines, so that students can understand hardware courses in depth. At the same time, teachers can combine with the direction of scientific research to increase students' curiosity in learning theory. The third part is "combined with the subject competition", which is an effective arrangement for students to practice extracurricular activities, and develops a suitable growth goals to continuously improve comprehensive quality and practical ability.

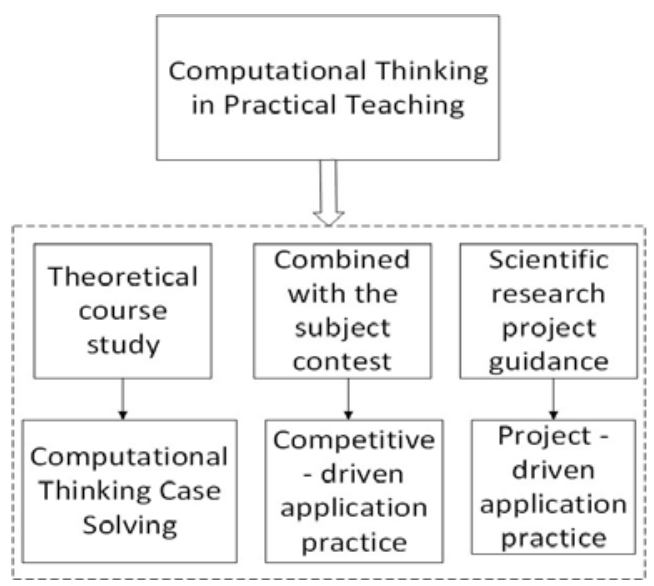

Fig. 1 Overall scheme of the hardware-based progressive model

\section{Guidance about research projects}

Students accepted some seemingly unrelated knowledge after learning theory of professional knowledge. At this point, some methods to help students systematize the knowledge are particularly important. Students should apply the knowledge to specific applications with the research projects, thus can achieve the established goals.

There are two categories for the scientific research projects we can participate in. One is student-led projects, and the other one is teacher-led research projects. For the former, the university student innovation and entrepreneurship training program (STITP) is the most typical. The latter mainly includes a variety of research projects undertaken by the teacher.These research projects are teacher-led, and many of them positively attempt international or domestic cutting-edge research and technology, which is helpful for some outstanding students in their senior grades.

According to the above principles, the authors have set two corresponding research directions for the students. One is "based on the Internet of things indoor air quality monitoring methods", which combined with the subject being studied. The other direction is based on Microsoft's Kinect somatosensory camera "Kinect-based golf attitude correction method". The part of the experimental process are shown in Fig. 2. 


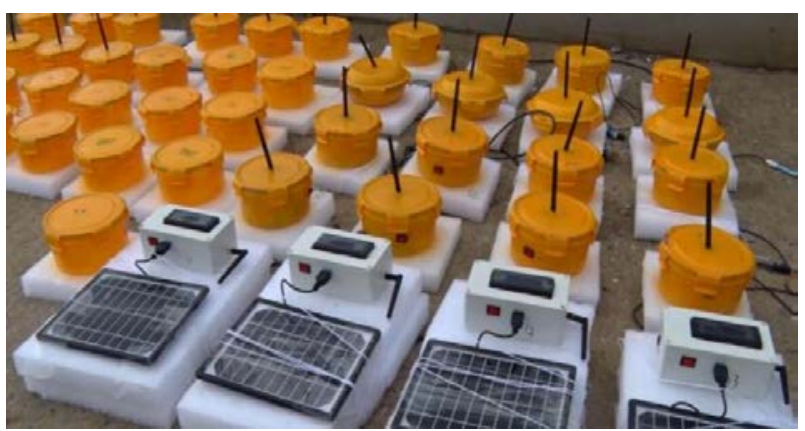

Fig. 2 Sensor nodes of monitoring water environment

\section{Theoretical course study}

The paper makes NJUPT information category of professional training programs as an example. First, some of the courses related to computer hardware are shown in Fig. 3. The main content of each course are closely linked and promote each other. When students learn one of these courses, then the relevant courses will have a great advantage to learn. If teachers can sort out and integrate the core contents of these courses, it would be easier for students to understand the relationship between the courses.

If learning basic theory courses and determining the direction of student research are at the same time, students would have motivation to learn some of the relevant knowledge and technology. In the case of wireless sensor networks, embedded development, signal processing, circuit design, programming and so on, the courses related to it are almost covered by computers, which are based on the "Indoor air quality monitoring method for home-based Internet of things". The vast majority of these courses are the core areas of the hardware curriculum. For example, the author is teaching the "micro-computer theory and interface technology". In the previous course which the author taught, one student said that "This course is out of date, and learn nothing useful remarks". Because coupled with the course is also more difficult, many students are not interested in learning. If you change the angle, from the completion of a specific application of the subject point of view, then the students will take the initiative to think about what needs to learn.

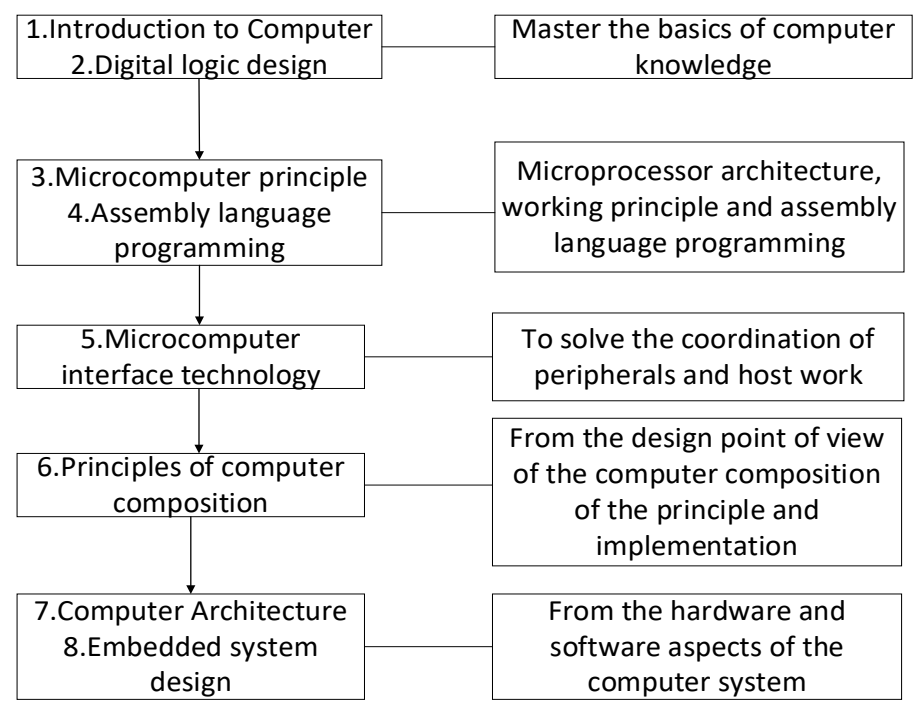

Fig. 3 Computer hardware course system

\section{Disciplines competition}

After the exercise and accumulation of theoretical study and research projects, many aspects of students' abilities are bound to be significantly improved. If the instructor can encourage and guide students to actively participate in some subject competitions related to their own interests or 
achievements in the previous project, undoubtedly, students' vision, teamwork awareness, innovation ability and independent thinking ability will be developed greatly. Through the judges' professional reviews and comments in the competitions, students can have a general understanding of the progress and achievements of their previous projects. Last but not least, if students can achieve good results in the competition, their interest and self-confidence in research will be enhanced a lot.

\section{Summary}

The progressive training mode of computer hardware talents is based on curriculum learning. It takes scientific research project as the carrier and the subject competition as the guidance. It is designed to fully and effectively mobilize the initiative and enthusiasm of college students, so that students can take the initiative to use the spare time to continuously enhance the ability of innovation and entrepreneurship. We hope to explore a set of highly feasible, operable personnel training model, which can not only contribute to the development of students, but also conducive to the teacher's work. Finally, a good win-win situation among the school, teachers and students can be formed.

\section{Acknowledgements}

This work was financially supported by the National Natural Science Foundation of P.R. China (61401221, 51608437, 51541804), China Postdoctoral Science Foundation (SBH16024), Teaching Reform Project of Tongda College of Nanjing University of Posts and Telecommunications (30615006).NJUPT Nature Science Foundation(NO.NY213037)

\section{References}

[1] S. Shen, Z.Q. Zou and F.J. Liu. The explorations and practice of undergraduate's learning tutorial system. HEILONGJANG EDUCATION, 2016, 2: 49-50.

[2] W.B. Guo, J.H. Li, J.G. Yang. Practical education for computer science undergraduates at East China University of Science and Technology. In proceedings of International conference on control, automation and systems engineering, 2011: 1-4.

[3] P. Wu, J.J. Xie. The implementation and harvests of task-driven in basic computer education at university. In proceedings of International conference on E-health networking, digital ecosystems and technologies, 2010, 2: 311-314.

[4] P. Smith. Bridging the gap in engineering education through student competition. ICCAS-SIZE, 2009: 1877-1877.

[5] J.J. Xie, J.H. Li. Blended learning in computer hardware course education. In proceeding of International conference on computer science and software engineering, 2008, 5: 905-908.

[6] S. Ristov, M. Stolikj, N. Ackovska. Awakening curiosity - Hardware education for computer science students. In proceesings of 34th Internatinal convention MIPRO, 2011: 1275-1280. 